\title{
From bone marrow to therapeutic applications: different behaviour and genetic/epigenetic stability during mesenchymal stem cell expansion in autologous and foetal bovine sera?
}

\author{
GAETANA A. TONTI and FERDINANDO MANNELLO* \\ Department of Biomolecular Sciences, Section of Clinical Biochemistry, University "Carlo Bo", I-61029 Urbino (PU), Italy
}

\begin{abstract}
Bone marrow-derived mesenchymal stem cells are a multipotent adult cellular population endowed with broad differentiation potential. Their regeneration capability, ease to undergo gene modifications, and immuno-suppressive capacity makes them optimal tools for tissue engineering, gene- and immuno-therapy. Due to the ever-increasing number of studies on the clinical applications of mesenchymal stem cells in regenerative medicine, these cells have become attractive targets in clinical transplantation. However, the identification and definition of mesenchymal stem cell culture media for their clinical application in cell therapy is currently a matter of strong discussion. Up to now, clinical studies have been conducted with mesenchymal stem cells cultured in foetal calf serum, and the chance of contamination or immunological reaction towards xenogeneic compounds must be taken into consideration. On the other hand, a serum-free medium without the addition of growth factors is not able to expand these cells in vitro; so the evaluation of which is best, among foetal calf serum, human serum (whether autologous or allogeneic) and platelet-rich plasma, is a "hot topic" urgently needing further research efforts. The need for the establishment of standardized protocols for mesenchymal stem cell preparations, in order not to interfere with their self-renewal and differentiation processes, assuring durable engraftment and long-term therapeutic effects, is evidently crucial. Therefore, the search for optimal culture conditions for the effective clinical-scale production of vast numbers of mesenchymal stem cells for cellular therapy is of paramount importance and the need for a robust passage from basic to translational research is fundamental.
\end{abstract}

KEY WORDS: AB serum, autologous serum, mesenchymal stem cell, platelet-rich medium

\section{The starting point}

The first isolation of fibroblast-like colonies from bone marrow falls back to 1970 , when Friedenstein reported the isolation of marrow-derived fibroblast-like cells, able to adhere to the plastic substrate of the cell culture plate (Friedenstein et al., 1970). On this basis, many approaches have been investigated and several protocols have been established to prepare primary cultures of bone marrow-derived mesenchymal stem cells (MSC) with more homogeneous cell population (Pittenger et al., 1999; Jiang et al., 2002). These MSCs are defined as self-renewable, multipotent progenitor cells with the capacity to differentiate into lineagespecific cells that form bone, cartilage, fat, tendon and muscle tissue; in addition to the capacity to differentiate into their natural derivatives, MSCs have the capability to differentiate into other types of cells, giving rise to hepatic, renal, cardiac and neural cells (Song and Tuan, 2004; Pansky et al., 2007). Moreover, MSCs have been isolated not only from bone marrow, but also from other tissues such as adipose tissue, skeletal muscle, trabecular bone, liver, brain, placenta, deciduous teeth, pancreas and tissue engineering (Zuk et al., 2002; Tuli et al., 2003; Porada et al., 2006; Satija et al., 2007; Spitkovsky and Hescheler, 2008).

Abbreviations used in this paper: BM, bone marrow; FCS, foetal calf serum; MSC, mesenchymal stem cell.

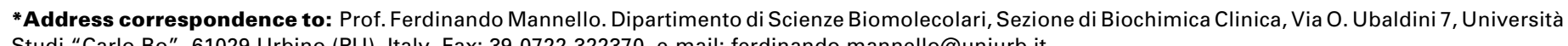
Studi “Carlo Bo", 61029 Urbino (PU), Italy. Fax: 39-0722-322370. e-mail: ferdinando.mannello@uniurb.it 
These cells have generated a great deal of interest; in fact, based on their facility to be isolated, extensive expansion rate, systemic engraftment capabilities and differentiation potential, MSCs find great utility and applicability in several therapeutic fields. MSCs are hypo-immunogenic, rendering them suitable for allogeneic transplantation, and exert the capacity to produce immuno-suppression after transplantation (Deans and Moseley, 2000; Porada et al., 2006, Spitkovsky and Hescheler, 2008; Le Blanc et al., 2008). The high plasticity and the capacity to differentiate, in addition to the capacity to migrate to the sites of injury, inflammation, or to tumour areas, makes MSCs promising candidates for use in regenerative medicine and tissue engineering (Satija et al., 2007), as well as serving as efficient delivery vehicles in site-specific therapy (Barry and Murphy, 2004, Chen et al., 2008).

So, much interest and hope have raised towards the potential clinical applications of MSCs; but multiple designations have been given to different MSC preparation protocols. In fact, MSCs can be derived from different tissues as starting material, with diverse isolation protocols, cultured and expanded in different media and conditions, rendering the preparation of these cells very heterogeneous (Mannello and Tonti, 2007). Taken together these variables may lead to such consequences involving: a) the selection of cell types and the composition of heterogeneous subpopulations, b) the expansion of different cell population with different potential, and c) the alteration of long-term fate of adult stem cells upon in vitroculture (Wagner and Ho, 2007; Spitkovsky and Hescheler, 2008). The recent controversies on the multilineage differentiation potential of some MSC preparations could depend on the lack of common standard protocols; in order to obtain the best cell culture condition, a number of methodological decisions need to be made; in particular special considerations are fundamental when MSCs are going to be used for patients' treatment (Sotiropoulou et al., 2007; Brinchmann, 2008), as culture conditions exert a prominent impact on transcriptome, proteome and cellular organization of bone marrow-derived MSCs (Wagner, et al., 2006; Phinney, 2007).

In this Issue of The International Journal of Developmental Biology, Dahl and colleagues present an interesting and insightful study, evidencing the importance of highly controlled culture conditions which may favour cell proliferation and differentiation, and that, in light of the therapeutic use of MSCs, must support their genomic and epigenetic stability (Dahl et al., 2008). Currently, there is extensive inconsistency among laboratories concerning the media, the culture surfaces, and the addition of supplementary factors for the successful isolation and expansion of MSCs (Fig. 1), that may thus end up with heterogeneous cell populations both in vivoexperiments and in clinical trials. On these bases, and in view of the therapeutic utility/applicability of MSCs, the need to define a more precise and standardized protocol for MSC expansion is urgently needed.

\section{From foetal bovine to autologous and/or allogeneic sera}

Bone marrow-derived MSCs (BMMSCs) were first identified by Fridenshtein, who demonstrated that when bone marrow is plated in foetal calf serum-containing medium, colonies of adherent fibroblast-like cells develop, which differentiate into bone and adipocytes (Friedenstein et al., 1970). Accordingly, most current protocols for in vitro culture of MSCs derived from bone marrow include foetal bovine or calf serum (FBS or FCS, respectively) as nutrient supplement (Satija et al., 2007). The widely accepted use of FBS or FCS is also true for human clinical trials approved by the

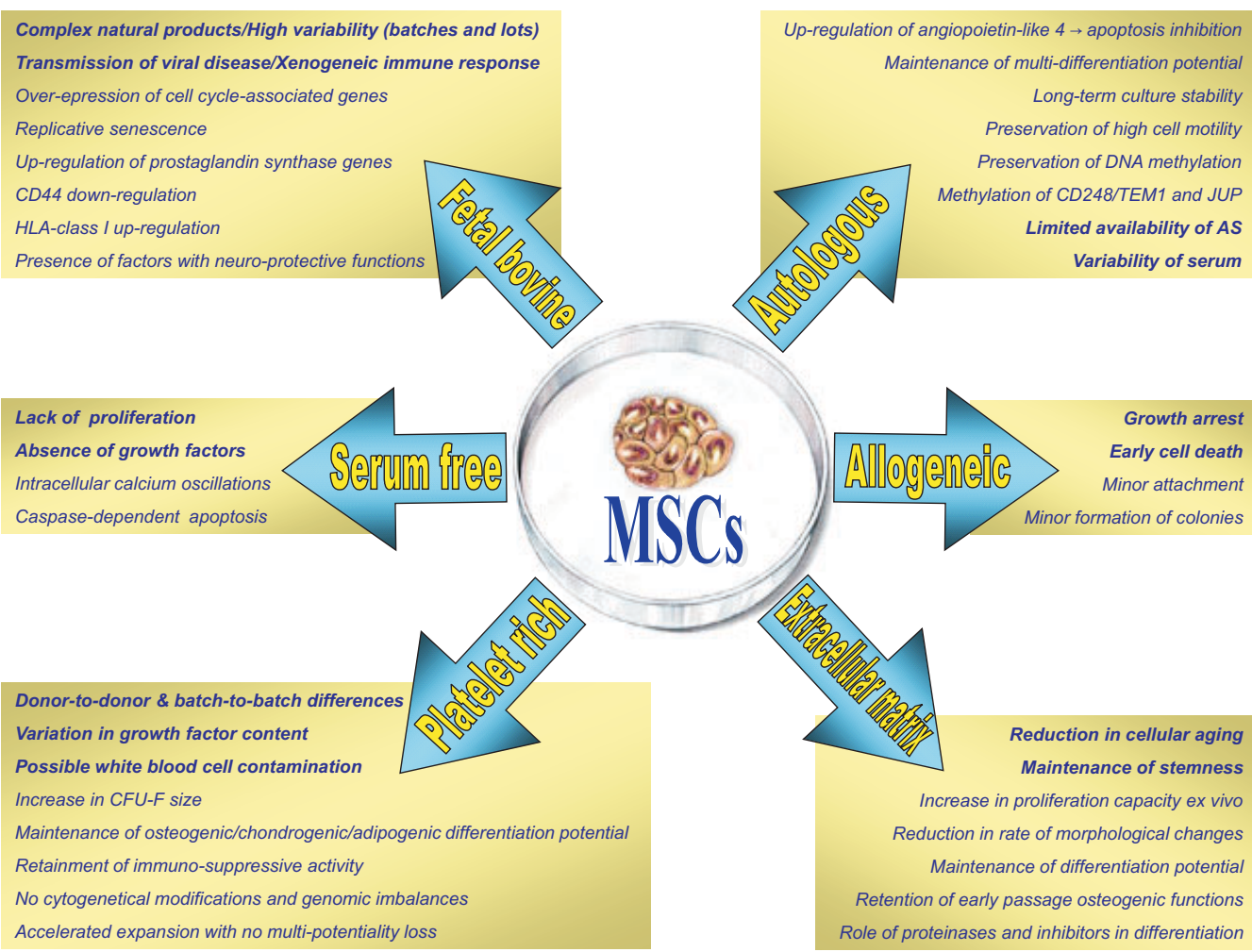

Fig. 1. Schematic representation of the pros and cons of cell culture media for mesenchymal stem cells (MSCs). Bone marrow-derived mesenchymalstem cells are a multipotent adult cellular population with multidifferentiation potential. Due to their regeneration and immuno-suppressive capabilities, together with thier facility to undergo gene modifications, they are useful tools for tissue engineering, gene- and immuno-therapy. The identification of a culture medium for the isolation and expansion of mesenchymal stem cells is a matter of strong literature discussion, as evident from the positive and negative effects which the various types of culture media have on both mesenchymal stem cell expansion/proliferation/differentiation and on bio-molecular pathways. These media range from serum-free to media supplemented with bovine foetal serum, autologous and allogeneic human sera, and platelet-enriched serum, as well as serum supplemented with extracellular matrix components. 
U.S. Food and Drug Administration (Horwitz et al., 1999); however, as FBS or FCS are complex natural products (which may vary from lot to lot even from a single manufacturer, and the quality and concentration of both bulk and specific proteins can affect cell growth), obtaining and maintaining successful and consistent cell fermentation can be difficult (Zheng et al., 2006; Mannello and Tonti, 2007). On the bases of the lack of a uniform approach for MSC expansion, a comprehensive study evaluated many culture parameters that may influence MSC expansion and differentiation. Several types of culture media, all supplemented with FBS, have been analyzed, reporting that variables such as basal medium, glucose concentration, stable glutamine, bone marrow mononuclear cell plating density, MSC passaging density, and plastic surface quality, all affect the final outcome of MSC isolation and expansion (Sotiropoulou et al., 2006). For example, the use of basic fibroblast growth factor, the most common growth supplement in MSC culture media, greatly increased the proliferation rate, and due to its down-regualtion of CD44 (involved in cell-cell and cell-matrix adhesion, and responsible for extravasation and homing), it may possibly reduce effective engraftment of transplanted MSCs. Basic fibroblast growth factor also up-regulated HLA-class I and induced low HLA-DR expression, increased the in vivo immuno-suppressive potential of MSCs and affected MSC multi-lineage differentiation capability, favouring differentiation toward the osteogenic lineage and limiting neurogenic potential (Sotiropoulou et al., 2006).

Even though extensively used in protocols for the expansion and differentiation of MSCs, FBS raises potential hazards that can not be neglected and its use has recently become a hot and very discussed topic due to the many complications and problems it raises (Mannello and Tonti, 2007); FBS may be an undesirable additive to cells that are expanded for therapeutic purposes in humans because bovine serum proteins may be internalized in stem cells and thus its use carries the risk of transmitting viral/ prion disease and proteins that may initiate xenogeneic immune responses (Shahdadfar et al., 2005, Dimarakis and Levicar, 2006) and may also cause immunological reactions due to the bovine protein attachment to cells in culture that act as antigenic substrates once transplanted (Heiskanen et al., 2007). Despite the very early recognition and adaptation of this concept in clinical work (Holst et al., 1990), only recently has wider application been allowed in emerging areas of stem cell research (Amit et al., 2004; Li et al., 2005), and MSC research has not been unscatched by this principle (Tao et al., 2005).

At a preclinical level, cell culture protocols using human blood derivatives should avoid the risk of problems associated with FBS, and autologous serum (AS) should also be taken into consideration until an "off-the-shelf" alternative becomes available (Dimarakis and Levicar, 2006). The clinical impact of these observations remains to be more accurately evaluated, but the use of AS instead of FBS prevented life-threatening arrhythmias after cellular cardiomyoplasty (Chachques et al.,2004); so, these bases strongly support the motivation to evaluate for MSC culture the use of AS serum or allogeneic human serum (alloHS) other than FBS. It has been demonstrated that expansion of human MSCs in AS in the absence of FBS and without any cytokines or growth factors is as effective as supplementing the culture with FBS with regard to both isolation and expansion (Stute et al., 2004; Shahdadfar et al., 2005). Human MSCs expanded in AS proliferate faster but differentiate more slowly than those expanded in FBS, and these differences are also evident in gene expression. For example, genes associated with the cell cycle are over-expressed in MSCs cultured in FBS and associated with prolongation of the cell cycle, leading to premature replicative senescence; on the other hand, angiopoietin-like 4, which is upregulated in MSCs expanded in AS, has been shown to inhibit apoptosis. In addition, other genes over-expressed in MSC in FBS are linked to differentiation into osteoblasts, adipocytes and chondrocytes, suggesting that FBS may be conductive toward differentiation. All together these patterns of gene expression suggest that MSCs grown in FBS have gone through some steps along the differentiation pathways that MSCs in AS have yet to pass through (Shahdadfar et al., 2005). Moreover, some of the genes up-regulated in MSC cultured in FBS, compared with those in AS, may be of interest for clinicians involved in defining protocols where the immunosuppressive properties are being exploited; in particular, the fact that several prostaglandin synthase genes are highly up-regulated in MSCs supplemented with FBS may move the "balance of power" towards FBS as serum supplement for these particular protocols (Shahdadfar et al., 2005). An interesting study reports that medium supplemented with AS, besides providing sufficient ex vivo expansion of bonemarrow MSCs maintaining their multi-differentiation potential, is more effective in promoting and preserving high motility in respect to medium with FBS (Kobayashi et al., 2005).

These reports point out that for what concerns the use of AS, if human MSCs are needed for therapeutic purposes, they can be expanded with AS serum supplement without risk of transcriptome instability: compared with cells expanded in FBS, human MSCs in $A S$ are less differentiated and remain transcriptionally stable over time in culture. So, the alternative of using AS seems quite feasible, even though it has been argued that it can be used only for the minority of clinical protocols involving low numbers of MSCs (Sotiropoulou et al., 2006); in fact, in this case, it is possible to obtain the appropriate volume of peripheral blood. Most types of cellular therapy need wide numbers of MSCs, which thus require large amounts of culture media and subsequently forbiddingly large volumes of peripheral blood (Sotiropoulou et al., 2006). However, the limitation of AS due to its availability, may be somehow revisited, because the concept that cells must be amplified before therapeutic use is based on a doubtful basis: the need to amplify cells because they are rare in the bone marrow (Berger et al., 2006). In fact, nothing demonstrates that daughter cells produced by native MSCs compensate by they numbers the properties lost or modified during amplification (Yamamoto et al., 2003; Stute et al., 2004; Schecroon and Delloye, 2004). Moreover, culture conditions could be adapted to the clinical application (e.g. in bone reconstruction, where the number of progenitors required could be limited and human serum seems of interest as it favours osteoblast differentiation) (Berger et al., 2006) and the most primary phenotypes have been described in poor media (Reyes et al., 2001; Pochampally et al., 2004); so it seems possible that low serum concentrations, while limiting cell proliferation, may favour production of cells for therapeutic use, justifying further studies.

The use of pooled human serum could not help to solve the possible problem of AS limited availability as evidenced by the contradictory results regarding allogeneic serum/plasma. Alloge- 
neic human serum (alloHS) results in the arrest of MSCs and their death (Shahdadfar et al., 2005) and human MSCs cultures supplemented with alloHS are dramatically different from those expanded in FBS or AS; in fact, fewer cells attach and form colonies and the attached cells survive through a few cell divisions but then die; human MSCs supplemented with alloHS never reach $60 \%$ sub-confluence in the first flask (Spees et al., 2004; Shahdadfar et al., 2005). These reports indicate that allogeneic differences in serum composition affect MSC survival and proliferation in vitro to a much greater extent than xenogeneic differences; however, the allogeneic proteins responsible for this growth inhibition are not yet known. On the other side, some studies have been successful in isolating and expanding MSC using AB serum (Yamaguchi et al., 2002; Anselme et al., 2002), even though other Authors reported growth arrest of MSCs after the first passage (Spees et al., 2004; Shahdadfar et al., 2005). It has been also demonstrated that adipose tissue-MSCs can be efficiently kept throughout long-term culture with $A B$ serum reaching the same final cumulative population doubling as FCS (Kocaomer et al., 2007).

\section{Comparing the extremes: serum-free and platelet-rich media}

In order to reliably and safely produce MSCs, the use of reagents that are defined, qualified and preferably derived from a non-animal source is desirable, and possible infection complications and host immune reactions have fuelled the investigation of alternative culture supplements.

Serum-free media have been investigated, but none seem to support the proliferation of MSCs in the absence of growth factors; in fact, serum-free media have not yet been defined for the isolation and expansion of MSCs, and studies using serum-free media refer only to differentiation studies in vitro (Lee et al., 2004; Tao et al., 2005). Serum-free culture experiments on animal models demonstrate the maintenance in culture of MSCs, but only after two passages in FCS-supplemented media (Lemnon et al., 1995), and due to MSC species-specific differences, even maintenance in serum-free conditions may not be applicable in the human system. Serum-free media can not promote MSC growth without the addition of cytokines or growth factors, possibly because serum induces intracellular calcium oscillations which are vital to stem cell proliferation and differentiation (Kuznetsov et al., 1997; Foreman, et al., 2006).

In order to avoid the many problems associated with the use of FBS, and to supply the limitation of a serum-free medium devoid of growth factors and cytokines, a commercial serum-free medium supplemented with a serum substitute (composed of all nutrients necessary for cell growth, such as growth factors, hormones, vitamins and binding proteins) was tested for the culture of MSCs (Meuleman et al., 2006). Its protein content is much lower when compared to FBS and its stable composition ensures a good reproducibility and biological activity from batch to batch. The use of this latter medium allowed to reduce the duration period of MSC amplification when compared to $\alpha$-MEM medium supplemented with FBS. The number of mesenchymal progenitors after primoculture and after the first passage was higher respect to classical medium, suggesting a better potential for expansion in commercial serum-free than $\alpha-M E M$, and a higher capacity to conserve MSC multipotentiality. The superiority of commercial serum-free medium (Meuleman et al., 2006) could be due to the presence of inhibitory factors but could also depend on the low levels of insulin, albumin, transferrin, that may play major roles in cell proliferation.

The use of human platelet lysate (PL) in a really serum-free medium seems a first step towards a defined MSC expansion procedure, and as platelets are a natural source of growth factors, PL may represent a powerful substitute for FBS, even though PL preparations may also have great differences from donor to donor, or from batch to batch; these differences make it difficult to standardize culture conditions in the presence of PL. Many investigators sought the in vitro expansion of MSCs in response to PLconditioned medium. A study dealing with MSC, derived not from bone marrow but from umbilical cord, demonstrated that human MSCs can be obtained and propagated to a clinical quantity in a completely bovine serum-free system, highlighting the applicability of clinical-grade MSCs propagated with human PL-conditioned medium, for hematopoiesis support, immune regulation and vascular regeneration (Reinisch et al., 2007). It has also been demonstrated that PL from platelet-rich plasma is able to promote BMMSC expansion, to decrease the time required to reach confluence, and to increase CFU-F size, as compared to FCS serum; moreover, MSCs cultured in PL and in fresh frozen plasma with platelets maintain their osteogenic, chondrogenic, and adipogenic differentiation properties and retain their immuno-suppressive activity (Doucet et al., 2005, Muller et al., 2006). In a study reporting the high efficacy of expansion of MSCs with human PL compared to FBS it is not clear whether the more robust MSC cultures produced by human PL only resulted from the rather constant growth factor activities (e.g., EGF, FGF and PDGF), evidencing that further studies are needed to understand the behaviour of MSCs prepared with human PL compared to that with FBS (Schallmoser et al., 2007). The use of platelet-rich plasma was also tested in an in vivo study on bone formation capacity as well as for the growth and differentiation capacity in vitro of MSCs, reporting that platelet-rich plasma supplemented medium yielded two-fold higher cell numbers compared to medium with FCS, retained a similar capacity to differentiate towards osteogenic, chondrogenic and adipogenic lineages and equalled in vivo bone formation (Vogel et al., 2006, Carrancio etal., 2008). The high reliability of the use of $P L$ has been strongly confirmed by an interesting study evidencing that, compared to FCS-supplemented culture conditions, PL-supplemented culture significant increased both CFU-F as well as cumulative stem cell numbers after expansion (Lange etal., 2007). These cells met all criteria for MSCs, such as plastic adherence, spindleshaped morphology, surface marker expression, lack of hematopoietic markers and differentiation potential into three mesenchymal lineages; moreover, MSCs were cytogenetically normal and retained their immune-privileged potential by suppressing allogeneic reaction of T-cells (probably due to the down-regulation of both MHC class I and class II genes) (Lange et al., 2007). Finally, gene expression profiles showed altered mRNA levels of some genes (e.g., involved in cell cycle and DNA replication), supporting the observation of accelerated MSC expansion in platelet-supplemented medium without loss of multi-potentiality.

It has been also demonstrated that PL preparations exert a dose-dependent effect on MSC expansion, probably due to the high concentration of natural growth factors contained in it; there is 
also a subtle difference in the morphology of MSCs cultured in the presence of different concentrations of $\mathrm{PL}$, compared to cells grown in standard FCS conditions (Bernardo et al., 2007). The biosafety of MSCs was also confirmed by karyotype analysis, reporting absence of any genomic imbalances (Bernardo et al., 2007). It has been also supported the hypothesis that, on the basis of a remarkable immunological functional plasticity of MSCs, the use of MSCs from PL culture/expansion, which seem to be endowed with a relatively low immune suppressive activity, could be more appropriate in reparative/regenerative cell-therapy approaches or in strategies aimed at improving hematopoietic/immune recovery after hematopietic stem cell transplantation. On the contrary, MSCs from FCS culture, seem to display a more pronounced immune suppressive function, and might be more suitable for preventing or treating alloreactive-related immune complications, such as severe GvHD and graft rejection in hematopietic stem cell transplantation and solid organ transplantation (Bernardo et al., 2007).

The use of thrombin activated platelet-rich plasma has also been investigated, due to the fact that platelet activation with thrombin closely imitates the physiologic activation of platelets, ensuring the bioactivity of secreted growth factors, and, via the release of small-membrane vesicles, has additional mitogenic effects; it has been demonstrated to enhance the proliferation of MSC (even though isolated from adipose tissue) without compromising differentiation capacity and immune-phenotype (Kocaoemer et al., 2007).

Even though the content of growth factors varies according to platelet concentration, preparation mode, white blood cell contamination and mechanism of platelet growth factor release, these results demonstrate that PL may be a powerful and safe substitute for FCS in the development of tissue- and cellular-engineered products in clinical settings using culture-expanded MSCs for transplantation applications. This approach provides a safe and optimal tool to elaborate cell therapy protocols by improving technical culture performances in terms of quality and quantity of MSCs produced, while reducing the patients' exposure to immunological reactions and to the risk of xenogeneic compounds. Based on cumulating evidence demonstrating the efficiency and safety of human PL or equivalent platelet rich plasma-derived preparations, the discussion on what is the best way to cultivate MSCs has surely been re-opened, requiring however further studies.

\section{And what about extracellular matrix components?}

An interesting feature of MSCs culture conditions, may be represented by the presence of different extracellular matrix biocompounds during their cultivation. It has been demonstrated that, when compared to tissue culture polystyrene, the growth of BMMSCs on a denatured collagen matrix significantly reduced the main manifestations of cellular aging (i.e., the attenuation of the ability to express major protective stress response component, HSP70), increased the proliferation capacity ex vivo of the cells, reduced the rate of morphological changes and maintained the differentiation potential (Mauney et al., 2004). For example, the maintenance of MSC osteogenic differentiation potential is primarily due to the ability of denatured collagen matrix to influence the retention of early passage osteogenic functions in late passage cells during $e x$ vivo expansion, in contrast to only enhancing attenuated late passage cellular functions during osteogenic differentiation, showing also that serum-associated factors play a role in influencing the retention of MSc osteogenic differentiation potential (Mauney et al., 2006). These results were further reinforced by studies evaluating the ability of a denatured collagen type I matrix to preserve MSC adipogenic potential during ex vivo expansion, indicating significant preservation of the ability of late passage MSCs ex vivo expanded on a denatured collagen matrix to express adipogenic markers in contrast to late passage MSCs expanded on tissue culture plastic (Mauney et al., 2005). An animal study was conducted on bovine MSCs analyzing the chondrogenic response during culture in different types of extracellular matrix in both serum free medium and medium supplemented with transforming growth factor beta1, showing that collagen II has the potential to induce and maintain MSC chondrogenesis, and prior to interaction with transforming growth factor beta1, to enhance differentiation (Bosnakovski et al., 2006); moreover, human MSCs cultured in a collagen type I hydrogel are able to undergo a distinct chondrogenic differentiation pathway, underling their utility in terms of predifferentiation or in situdifferentiation of MSCs in collagen hydrogels for articular cartilage repair (Noth et al.,2007).

MSCs were also cultured on an extracellular matrix (ECM) made by bone marrow cells to try to reconstitute the MSC niche. This ECM promoted replication of mesenchymal progenitors and retention of their multi-potentiality, indicating that the marrow ECM facilitates expansion of mesenchymal progenitors hypothesizing that it plays important roles in the maintenance of MSC stemness (Chen et al., 2007). Interestingly, transplantation of these cells, expanded on the marrow-derived ECM, into immuno-compromised mice generated five times more bone and eight times more hematopoietic marrow compared with mesenchymal colony-forming units expanded on plastic (Chen et al., 2007).

So, MSCs when cultured on tissue plastic lose their unique properties, indicating that a critical feature of the marrow microenvironment that facilitates retention of stem cell properties is missing in such culture systems. The ability of matrix components to preserve the peculiar characteristics of MSCs following extensive ex vivo expansion represents a novel culture technique to expand functional progenitors for tissue engineering applications.

The important role of the proteinases degrading ECM components in maintaining and influencing the behaviour of MSC has been also recently overviewed (Mannello, 2006), highlightening that matrix metalloproteinases and their inhibitors are implicated in several differentiation events; the proliferative and pro-differentiating effects of the proteolytic cascade due to Matrixins may have regulatory effects on the differentiation of MSC (including those of myoblastic, osteoblastic, chondroblastic, neural and adipoblastic lineages)(Mannello et al., 2006; Tonti et al., 2008).

\section{The "dark side" of in vitro MSC expansion}

Of great importance in cell culture is not only to remove possible contamination from the culture medium due to animal serum antigens, but also to obtain large numbers of cells for use in biomedical procedures, clinics and therapy. MSCs lack the activity of the immortalized enzyme telomerase which can counteract senescence by maintaining telomerase sequence (Zimmerman et al., 2003; Serakinci, 2004) and thus have defined ex vivo proliferation capability, reaching senescence and losing their 
multi-lineage differentiation potential after $30-40$ population doublings in culture; so, it may be crucial to prolong the replicative capacity of MSCs without impairing their multi-potentiality (Simonsen et al., 2002). To solve these problems, investigators can extend the life span on MSCs via retrovital transfection of human telomerase reverse transcriptase (hTERT) and human papillomavirus type 16 E6 and/or E7 genes (Takeda et al., 2004). Forced ectopic expression of hTERT in MSCs can greatly extend their lifespan maintaining their differentiation potential. However, it has been demonstrated that a hTERT-transduced cell line, showed loss of contact inhibition, anchorage independence and tumor formation (Reiser et al., 2005). These data suggest that MSCs can be prone to the neoplastic transformation and thus these cells may be used in both the development of novel anticancer therapeutics and in tissue engineering and transplantation protocols (e.g., use of hTERT-immortalized MSCs). So, MSCs represent an excellent model for studying telomerase gene expression with direct implications for cell therapies and tissue engineering (Satija et al., 2007).

When hTERT is ectopically expressed in MSCs, neoplastic changes are accumulated suggesting that MSCs can be targets for neoplastic transformation (Serakinci, 2004), and long-term cultures of telomerase-transduced adult human MSCs may evolve spontaneously genetic changes leading to tumorigenicity in immunodeficient mice, indicating that these transduced cells represent cancer cells with hierarchical tumorigenicity, providing new models to explore the stem cell hypothesis of cancer (Burns et al., 2005).

In regard to gene therapy application of MSCs, we can not rule out the possibility that gene-transduced bone marrow cells will become tumourigenic in patients several decades after commencement of cell therapy (Toyada et al., 2007). What must be taken into account is that even when non oncogenic genes are introduced for cell-based therapy to increase cell growth and prolong life span, cases of leukemia have occurred in patients treated with gene-modified lymphocytes (Hacein-Bey-Abina et al., 2003). There are strong links between normal stem cells and cancer stem cells, suggesting that stem cells are targets for neoplastic transformation, thus raising the question regarding the possibilities that MSCs undergo malignant transformation; however, despite having stem cells properties, when passaged in culture, MSCs reduce their proliferative rate and enter replicative senescence (Dick, 2003). A recent study has investigated the susceptibility to transformation of human bone marrow derivedMSCs at different in vitroculture points, reporting that telomerase activity and hTERT were not expressed, telomeres shortened during the culture period and alternative lengthening of telomere was not evidenced in MSCs (Bernardo et al., 2007). All these reports highlight contrasting results, suggesting that the research in this field is in its infancy and more studies are needed to clarify if MSCs can be safely expanded in vitro and susceptible to malignant transformation, in order to render these cells suitable for cell therapy approaches.

Self-renewal and differentiation potential is the feature of stem cells and the roles for cancer stem cells has been demonstrated for some cancers, however the origin of cancer cells remains elusive (Wu, 2008). Cancer stem cells may derive from mutations occurring in multi-potential stem cells, being not the cause, but the consequence of carcinogenesis, where cancer cells may be caused by disturbance of self-renewal and differentiation $\mathrm{Wu}$, 2008). In this respect, recent reports have proposed the hypothesis that some carcinomas are derived from mesenchymal precursors (Rubio et al., 2008), and that human MSCs exposed to tumor-conditioned media over a prolonged time assume a carcinoma-associated fibroblast-like myofibroblastic phenotype, exhibiting the ability to promote tumor cell growth both in vivoand in vitro, this is the first evidence that that human MSCs become activated and resemble carcinoma-associated myofibroblasts (Mishra et al., 2008). It is well known that cancer epigenetic may be also affected by DNA methylation; it is associated with longterm gene silencing and the methylation of tumor suppressor genes may lead to cellular transformation (Laird, 2005). So, a question is reasonably raising: can methylation affect genomic and epigenetic stability of MSCs upon extended culture or may hypermethylation affect the fate of cultured MSCs?

\section{Methylation changes during bone marrow MSC cul- ture: what lies ahead?}

The use of MSCs for therapeutic applications is based on their subsequent large-scale in vitro expansion, which may lead to genetic and epigenetic instabilities; however, up to now, data on MSC transformation are very few (Rubio et al.,2005), showing normal karyotypes and DNA copy numbers in long-term culture (Rubio et al.,2005; Zhang et al., 2007; Bernardo et al., 2007). Telomeric deletions have been reported (Meza-Zepeda et al.,2008), indicating that chromosomal aberrations may occur, but with a very low incidence (Bernardo et al., 2007). To date there is no report highlighting whether both human and animal serum sources affect genomic and epigenetic stability of MSCs in extended culture. In this respect, an important feature of epigenetics is DNA methylation, where methylation of cytosines in cytosinephosphate-guanine may favour genomic integrity ensuring correct gene expression. In this Issue of The International Journal of Developmental Biology a timely study has been reported, demonstrating that MSCs cultured in AS maintain long-term genomic stability and preserve DNA methylation better that in FBS, indicating that up- or down-regulation of genes is unlikely due to genomic alterations (Dahl etal., 2008). Although contradictory results have been described about the alterations in DNA copy number on a number of chromosomes during MSCs culture in AS and FBS (Bernardo et al., 2007), Dahl et al. report that all AS-supplemented cultures yielded normal gene copy numbers for all donors studied, strengthening the concept that genomic instability in BMderived MSC culture depends on donor variability and/or variability between bovine serum lots. From these results, it seems that the regulation of genes in AS or FBS is not due to genomic modifications; in fact, there are studies suggesting lack of correlation between DNA methylation and transcription, as no gene with altered methylation pattern significantly modified its expression pattern (Shahdadfar, et al., 2005). Moreover, Dahl et al. showed that among those genes undergoing methylation changes in MSCs, most become methylated rather than demethylated; in particular, CD248/TEM1(endosialin) and JUP(junction plakoglobin or $\gamma$-catenin) genes are involved in cell adhesion and migration, genomic stability and oncogenesis. Interestingly, among the differently methylated genes, there were more genes stably unmethylated in $A S$ respect to FBS, suggesting that $A S$ has a 
greater capacity that FBS in maintaining the unmethylated state upon long-term culture. According to the hypothesis that BMMSCs cultured in FBS seem to differentiate more readily than in AS (suggesting an early differentiation program in FBS) (Shahdadfar et al., 2005), it is conceivable that AS contributes to perpetuating a less differentiated state than FBS; however, whether this will be detectable at the DNA methylation level in a whole-genome scale or if most unmethylated genes in BMMSCs are also unmethylated in vivo is a matter of future perspectives due to the ever growing potential use of MSCs in regenerative medicine.

MSCs are believed as potential therapeutic targets for cell and gene-therapy-based approaches towards several different kinds of diseases, such as myocardial infarcts, graft-versus-host disease, Crohn's disease, cartilage and meniscus repair, neurodegenerative and muscle degenerative disease, stroke and spinal cord injury (Caplan, 2007, Le Blanc et al., 2008; Dezawa, 2008). Due to their self-renewal potential, MSCs are strong candidates for delivering genes; however, although expanded MSCs have great proliferation and differentiation potential in vitro, there are limitations with the biology of these cells in vivo. Up to now, MSCs didn't maintain long-lasting therapeutic effects from a true self-renewing stem cell population. The loss of extensive in vivoself-renewal capacity may be due to the extensive expansion of MSCs in existing in vitro expansion systems, suggesting that the original stem cell population may no longer exist. Rather, the in vivo biology of expanded cell populations suggests that they may be a heterogeneous population of MSCs produced after several generations in vitro, and contain different types of mesenchymal cell progeny that have limited proliferation potential and responsiveness for terminal differentiation along mesenchymal and non-mesenchymal lineages (Reiser et al.,2005).

The "sore point" of the actual idea of MSCs may lie in the extensive proliferation capacity that we may be taking advantage of, where, extensive passages may produce cells terminally ready to differentiate, but can not grow anymore or anywhere (Rombouts and Ploemacher, 2003). The lack of telomerase activity in MSCs may not be a paradox after all. The stem cell nature of the original MSC may be lost with current expansion systems that appear to give great promise in vitro, but without in vivo efficacy. Therefore, it may no longer be surprising that their in vivo engraftment may no longer exist (Reiser et al., 2005).

For the clinical use of MSCs, standards are needed and the clinical grade production necessitates to adhere to "good manufacturing practices" to insure the delivery of a "cell drug" that is safe, reproducible and efficient (Sensebè, 2008). Currently, there is extensive inconsistency among laboratories regarding the media and the addition of supplementary factors for the successful isolation and expansion of MSCs, that ends up with heterogeneous cell populations both in in vitro experiments and in clinical trials. The source and the freshness of the starting material, culture media used, presence of animal sera, cytokines, growth factors, all have a significant impact on: the cell type components and heterogeneity of the initial population, differential expansion of specific subsets, with different potentials of the end products, and long-term functional fate of MSCs as well as of other types of progenitors that are co-cultivated with them (Caterson et al., 2002; Ho et al., 2008).

The elaboration of a culture medium, adapt to the production of MSCs for the clinical application of cell therapy, remains a crucial matter. Since, at the moment, a serum-free medium with no growth factors is not able to amplify these cells in vitro, the type of serum used (FBS or human serum, allogeneic or autologous, serum or plasma) is a matter of strong discussion and effort (Berger et al., 2006; Mannello et al., 2007). Even though clinical studies with MSCs cultured with FBS have not shown any marked secondary effect, the possible contamination or immunologic reactions have not been investigated; and moreover, follow-up is too short to evaluate the long-term effects (Horwitz et al., 2002; Le Blanc etal., 2004). In theory, using human serum should avoid the risk of these secondary effects, suggesting not to discard the idea of using human serum, in particular autologous serum (Mannello, 2006). The choice of the best media for MSC may rely on its ability to obtain MSC with characteristics more similar as possible to those of native MSCs, which requires to identify progenitors in fresh bone marrow (involving quality control of the mesenchymal compartment of non-manipulated grafts) and to evaluate the selfrenewal capacity of MSCs with suitable tools (Berger et al., 2006; Mannello et al., 2007)

In conclusion, different pre-operative protocols lead to MSClike cell cultures and the quality of preparation from different laboratories is very diverse with heterogeneous products (Fig. 1). All these reports, point out to the urgent need for the establishment of standardized approaches and protocols for MSC preparations, in order not to interfere with MSC self-renewal and differentiation processes as well as gene methylation, assuring durable engraftment and long-term therapeutic effects of MSCs; in particular special considerations are necessary if the cells are to be used for the treatment of patients. Therefore, the search for the optimal culture conditions for the effective clinical-scale production of vast numbers of MSCs for cellular therapy in transplantation, immuno-therapy and regenerative medicine is of paramount importance and the need for a robust passage from basic to translational research is thus fundamental.

Although we have not overviewed all aspects of the best conditions for MSC culture and even though at the end many questions remain unsolved, it is essential to know and consolidate the foundations in order to reach the future perspectives; the resolution of this demanding task is not immediately at hand, but such a challenging issue as the search of MSC optimal culture conditions, surely makes up with all the efforts.

\section{Acknowledgement}

We would also like to thank Mrs Eleonor Cencherle for assisting in English revision.

\section{References}

AMIT, M., SHARIKI, C. and MARGULETS, V. (2004). Feeder layer- and serum-free culture of human embryonic stem cells. Biol Reprod 70: 837-845.

ANSELME, K., BROUX, O. and NOEL. B. (2002). In vitro control of human bone marrow stromal cells for bone tissue engineering. Tissue Eng 8: 941-953.

BARRY. F. P. and MURPHY, J. M. (2004). Mesenchymal stem cells: clinical application and biological characterization. Int J Biochem Cel/ Bio/36: 568-584.

BERNARDO, M. E., AVANZINI, M. A., PEROTTI, C., COMETA, A. M., MORETTA, A., LENTA, E., DEL FANTE, C., NOVARA, F., DE SILVESTRI, A., AMENDOLA, G., ZUFFARDI, O., MACCARO, R. and LOCATELLI, F. (2007). Optimization of in vitro expansion of human multipotent mesenchymal stromal cells for celltherapy approaches: further insights in the search for a fetal calf serum substitute. J Cell Physio/211: 121-130.

BERNARDO, M. E., ZAFFARONI, N., NOVARA, F., COMETA, A. M., AVANZINI, M. 
A., MORETTA, A., MONTAGNA, D., MACCRIO, R., VILLA, R., DAIDONE, M. G., ZUFFARDI, O. and LOCATELLI, F. (2007). Human bone marrow derived mesenchymal stem cells do not undergo transformation after long-term in vitro culture and do not exhibit telomere maintenance mechanisms. Cancer Res 67: 9142-9149.

BOSNAKOVSKI, D. M, MIZUNO, M., KIM, G., TAKAGI, S., OKUMURA, M. and FUKINAGA, T. (2006). Chondrogenic differentiation of bovine bone marrow mesenchymal stem cells (MSCs) in different hydrogels: influence of collagen type II extracellular matrix on MSc chondrogenesis. Biotechnol Bioeng 93: 1152-1163.

BRINCHMANN, J. E. (2008). Expanding autologous multipotent mesenchymal bone marrow stromal cells. J Neurol Sci. 265: 127-130.

BURNS, J.S., ABDALLAH, B. M., GULDBERG, P., RYGAARD, J., SCHRODER, H. D. and KASSEM, M. (2005). Tumorigenic heterogeneity in cancer stem cells evolved from long-term cultures of telomerase-immortalized human mesenchymal stem cells. Cancer Res 65: 3126-3135.

CAPLAM A. I. (2007). Adult mesenchymal stem cells for tissue engineering versus regenerative medicine. J Cell Physio/231: 341-347.

CARRANIO, S., LOPEZ-HOLGADO, N., SANCHEZ-GUIJO, F. M., VILLARON, E., BARBADO, V., TABERA, S., DIEZ-CAMPELO, M., BLANCO, J., SAN MIGUEL, J. F. and DEL CANIZO, M. C. (2008). Optimization of mesenchymal stem cell expansion procedures by cell separation and culture conditions modification. Exp Hemato/(DOI:10.1016/j.exphem.2008.03.012).

CATERSON, E. J., NESTI, L. J. and DANIELSON, K. G. (2002). Human marrowderived mesenchymal progenitor cells: isolation culture, expansion and analysis of differentiation. Mol Biotechnol 20: 245-256.

CHACHQUES, J. C., HERREROS, J. and TRAININI, J. (2004). Autologous human serum for cell culture avoids the implantation of cardioverte-defibrillators in cellular cardiomyoplasty. Int J Cardio/95: S29-33.

CHEN, X. D., DUSEVICH, V., FENG, J. Q., MANOLAGAS, S. C. and JILKA, R. L. (2007). Extracellular matrix made by bone marrow cells facilitates expansion of marrow-derived mesenchymal progenitor cells and prevents their differentiation into osteoblasts. J Bone Miner Res 22: 1943-1956.

CHEN, Y., SHAO, J. Z., XIANG, L. X. and ZHANG, G. R. (2008). Mesenchymal stem cells: a promising candidate in regenerative medicine. Int $\mathrm{J}$ Biochem Cell Biol 40: 815-820.

DAHL, J. A., DUGGAL, S.,COULSTON, N., MILLAR, D., MELKI, J., SHAHDADFAR, A., BRINCHMANN, J. E. and COLLAS, P. (2008). Genetic and epigenetic instability of human bone marrow mesenchymal stem cells expanded in autologous serum or fetal bovine serum. Int J Dev. Biol 52: 1033-1042.

DEANS, R. J. and MOSELEY, A. B. (2000). Mesenchymal stem cells: biology and potential clinical uses. Exp Hemato/28: 875-884.

DEZAWA, M. (2008). Systematic neuronal and muscle induction systems in bone marrow stromal cells: the potential for tissue reconstruction in neurodegenerative and muscle degenerative diseases. Med Mol Morpho/41: 14-19.

DICK, J. E. (2003). Breast cancer stem cells revealed. Proc Nat/ Acad Sci 100: 3547-3549.

DOUCET, C., ERNOU, I., ZHANG, Y.M LLENSE, J.R., BEGOT, L., HOLY, X. and LATAILLADE, J. J. (2005). Platelet lysates promote mesenchymal stem cell expansion: a safety substitute for animal serum in cell-based therapy applications. J Cell Physio/205: 228-236.

DIMARAKIS, I. and LEVICAR, N. (2006) cell culture medium composition and translational adult bone marrow-derived stem cell research. Stem Cells 24: 1407-1408.

FOREMAN, M. A., SMITH, J. and PUBLICOVER, S. J. (2006). Characterization of serum-induced $\mathrm{Ca} 2+$ oscillations in primary bone marrow stromal cells. $\mathrm{J}$ Cell Physio/206: 664-671.

FRIEDENSTEIN, A. J., CHAIALAKHJAN, R.K., and LALYKINA, K.S. (1970). The development of fibroblast colonies in monolayer cultures of guinea-pig bone marrow and spleen cells. Cell Tissue Kinet 3: 393-403.

HACEIN-BEY-ABINA, S., VON KALLE, C. and SCHMIDT, M. (2003). LMO2associated clonal $T$ cell proliferation in two patients after gene therapy for SCIDX1. Science 302: 415-419.

HEISKANEN, A., SATOMAA, T. and TIITINEN, S. (2007). N-GlycolyIneuraminic acid xenoantigen contamination of human embryonic and mesenchymal stem cells is substantially reversible. Stem Cells 25: 197-202.
HO, A. D., WAGNER, W. and FRANKE, W. (2008). Heterogeneity of mesenchymal stromal cell preparation. Cytotherapy 10: 320-330.

HOLST, N., BERTHEUSSEN, K. and FORSDAHL, F. (1990). Optimization and simplification of culture conditions in human in vitro fertilization (IVF) and preembryo replacement by serum-free media. $J$ In Vitro Fert Embryo Transf 7: 47-53.

HORWITZ, E. M., GORDON, P. L. and FITZPATRICK, L. A. (1999). Transplantability and therapeutic effects of bone-marrow-derived mesenchymal cells in children with osteogenesis imperfecta. Nat Med5: 309-313.

HORWITZ, E. M., GORDON, P. L and KOO, W. K. (2002). Isolated allogeneic bone marrow-derived mesenchymal cells engraft and stimulate growth in children with osteogenesis imperfecta: Implications for cell therapy of bone. Proc Nat/ Acad Sci USA 99: 8932-8937.

JIANG, Y., JAHAGIRDAR, B. N., REINHARDT, R. L., SCHWARTZ, R. E., KEENE, C. D., ORTIZ-GONZALES, X. R., REYERS, M., LENVIK, T., LUND, T., BLACKSTAD, M., DU, J., ALDRICH, S., LISBERG, A., LOW, W. C., LARGAESPADA, D. A. and VERFAILLIE, C. M. (2002). Pluripotency of mesenchymal stem cells derived from adult marrow. Nature 418: 41-49.

LONES, P. A. and TAKAI, D. (2001). The role of DNA methylation in mammalian epigenetics. Science 293: 1068-1070.

KOCAOMER, A., KERN, S., KLUTER, H and BIEBACK, K. (2007). Human AB serum and thrombin-activated platelet-rich plasma are suitable alternatives to fetal calf serum fort he expansion of mesenchymal stem cells from adipose tissue. Stem Cells 25; 1270-1278.

KOBAYASHI, T., WATANABE, H., YANAGAWA, T., TSUTSUMI, S., KAYAKABE. M., SHINOZAKI, T., HIGUCHI, H. and TAKAGISHI, K. (2005). Motility and growth of human bone-marrow mesenchymal stem cells during ex vivo expansion in autologous serum. $J$ Bone Joint Surg Br87: 1426-1433.

KUZNETSOV, S. A., FRIEDENSTEIN, A. J. and ROBEY, P. G. (1997). Factors required for bone marrow stromal fibroblast colony formation in vitro. $\mathrm{Br} J$ Hemato/97: 561-570.

LAIR, P. W. (2005). Cancer epigenetics. Hum Mol Genet 14: R65-R76.

LANGE, C., CAKIROGLU, F., SPIESS, A-N., CAPALLO-OBERMANN, H., DIERLAMM, J. and ZANDER, A. R. (2007). Accelerated and safe expansion of human mesenchymal stromal cells in animal serum-free medium for transplantation and regenerative medicine. J Cell Physio/213: 18-26.

LE BLANC, K., RAMUSSON, I. and SUNDBERG, B. (2004). Treatment of severe acute graft-versus-host-disease with third party haploidentical mesenchymal stem cells. Lancet 363: 1439-1441.

LE BLANC, K., FRASSONI, F., BALL, L., LOCATELLI, F., ROELOFS, H., LEWIS, I., LANINO, E., SUNDBERG, B., BERNARDO, M. E., REMBERGER, M., DINI, G., EGELER, R. M., BACIGALUPO, A., FIBBE, W. and RINGDEN, O. (2008). Mesenchymal stem cells for treatment of steroid-resistant, severe, acute graftversus-host-disease: a phase II study. Lancet 371: 1579-1586.

LEE, J. W., KIM, Y. H and PARK, K. D. (2004). Importance of integrin beta-1mediated cell adhesion on biodegradable polymers under serum depletion in mesenchymal stem cells and chondrocytes. Biomaterials 25: 1901-1909.

LENNOM, D. P., HAYNESWORTH, S. E. and YOUNG, R.G. (1995). A chemically defined medium supports in vitro proliferation and maintains the osteochondral potential of rat marrow-derived mesenchymal stem cell. Exp Cell Res219: 211222.

LI, Y., POWELL, S. and BRUNETTE, E. (2005). Expansion of human embryonic stem cells in defined serum-free medium devoid of animal-derived products. Biotechnol Bioeng 91: 688-698.

MANNELLO. F. (2006). Multipotent mesenchymal stromal cell recruitment, migration, and differentiation: what have matrix metalloproteinases got to do with it? Stem Cells 24:1904-1907.

MANNELLO, F. and TONTI, G. A. (2007). No breakthroughs for human mesenchymal and embryonic stem cell culture: conditioned medium, feeder layer or feeder-free; medium with fetal calf serum, human serum or nonconditioned medium or ad-hoc formula? All that glitters is not gold! Stem cells 25:1603-1609.

MANNELLO, F., TONTI, G. A. M., BAGNARA, P. and PAPA, S. (2006). Role and function of matrix metalloproteinases in the differentiation and biological characterization of mesenchymal stem cell. Stem Cells 24: 475-481.

MAUNEY, J. R., KAPLAN, D. L. and VOLLOCH, V. (2004). Matrix-mediated retention of osteogenic differentiation potential by adult bone marrow stromal 
cells during ex vivo expansion. Biomaterials 25: 3233-3243.

MAUNEY, J. R., KIRKER-HEAD, C., ABRAHAMSON, L., GRONOWICZ, G, VOLLOCH, V. and KAPLAN, D. L. (2006). Matrix-mediated retention of in vitro osteogenic differentiation potential and in vivo bone-forming capacity by human adult bone marrow-derived mesenchymal stem cells during ex vivo expansion. $\checkmark$ Biomed Mater Res A 79: 464-475.

MAUNEY, J. R., VOLLOCH, V. and KAPLAN, D. L. (2005). Matrix-mediated retention of adipogenic differentiation potential by adult bone marrow stromal cells during ex vivo expansion. Biomaterials 26: 6167-6175.

MEULEMAN, N., TONDREAU, T., DELFORGE, A., DEJENEFFE, M., MASSAY, M., LIBERTALIS, M., BRON, D. and LAGNEAUX, L. (2006). Human marrow mesenchymal stem cell culture: serum-free medium allows better expansion than classical $\alpha$-MEM medium. Eur J Haemato/76: 309-316.

MISHRA, P. J., MISHRA, P. J., HUMENIUK, R., MEDINA, D. J., ALEXE, G., MESIROV, J. P., GANESAN, S., GLOD, J. W. And BANERJEE, D. (2008). Carcinoma-associated fibroblast-like differentiation of human mesenchymal stem cells. Cancer Res 68: 4331-4339.

MULLER, I., KORDOWICH, S., HOLZWARTH, C., SPANO, C., ISENSEE, G., STAIBER, A., VIEBAHN, S., GIESEKE, F., LANGER, H., GAWAZ, M. P., HORWITZ, E. M., CONTE, P., HANDHRETINGER, R. and DOMINICI, M. (2006). Animal serum-free culture conditions for isolation and expansion of multipotent mesenchymal stromal cells from human BM. Cytotherapy 8: 437444.

NOTH, U., RACKWITZ, L.,HEYMER, A., WEBER, M., BAUMANN, B., STEINERT, A., SCHUTZE, N., JAKOB, F. and EULERT, J. (2007). Chondrogenic differentiation of human mesenchymal stem cells in collagen type I hydrogels. J Biomed Mater Res A. 83: 626-635.

PANSKY, A., ROITZHEIM, B. nad TOBIASCH, E. (2007). Differentiation potential of adult human mesenchymal stem cells. Clin Lab 53: 81-84.

PHINNEY, D. G. (2007). Biochemical heterogeneity of mesenchymal stem cell populations: clues to their therapeutic efficacy. Cell Cycle 6: 2884-2889.

PITTENGER, M. F., MACKAY, A. M., BECK, S. C., JAISWAL, R. K., DOUGLAS, R., MOSCA, J. D., MOORMAN, M. A., SIMONETTI, D. W., CRAIG, S. and MARSHAK, D. R. (1999). Multilineage potential of adult human mesenchymal stem cells. Science 284: 143-147.

POCHAMPALLY, R.R., SMITH, J. R. and YLOSTALO, J. (2004). Serum deprivation of human marrow stromal cells selects for a subpopulation of early progenitpr cells with enhanced expression of OCT-4 and other embryonic genes. Blood 103: 1647-1652.

PORAGA, C. D., ZANJANI, E. D. and ALMEIDA-PORAD, D. (2006). Adult mesenchymal stem cells: a pluripotent population with multiple applications. Curr Stem Cell Res Ther1: 365-369.

REINISC, A., BARTMANN, C., ROHDE, E., SCHALLMOSER, K., BJELIS-RADISIC V., LANZER, G., LINKESCH, W. and STRUNK, D. (2007). Humanized system to propagate cord blood-derived multipotent mesenchymal stromal cells for clinical applications. Regen Med2: 371-382

REYES, M., LUND, T. and LENVIK, T. (2001). Purification and ex vivo expansion of postnatal human marrow mesodermal progenitor cells. Blood98: 2615-2625.

ROMBOUTS, W. J. and PLOEMACHER, R. E. (2003). Primary murine MSC show highly efficient homing to the bone marrow but lose homing ability following culture. Leukemia 17: 160-170.

RUBIO, D., GARCIA-CASTRO, J., MARTIN, M. C., DE LA, F. R., CIGODOSA, J. C., LLOYD, A. C. and BERNARD, A. (2005). Spontaneous human adult stem cell transformation. Cancer Res 65: 3035-3039.

RUBIO, D., GARCIA, S., DE LA CUEVA, T., PAZ, M. F., LLOYD, A. C., BERNAD, A. and GARCIA-CASTRO, J. (2008). Human mesenchymal stem cell transformation is associated with a mesenchymal-epithelial transition. Exp Cell Res 314: 691-698.

SATIJA, N. K., GURUDUTTA, G. U., SHARM, S., AFRIN, F., GUPTA, P., VERMA, Y. K., SINGH, V. K., and TRIPATHI, R. P. (2007). Mesenchymal stem cells: molecular targets for tissue engineering. Stem Cell Dev 16: 7-23.

SCHALLMOSER, K., BARTMANN, C., ROHDE, E., REINISCH, A., KASHOFER, K. STADELMEYER, E., DREXLER, C., LANZER, G., LINKESCH. W. and STRUNK. D. (2007). Human platelet lysate can replace fetal bovine serum for clinical-scale expansion of functional mesenchymal stromal cells. Transfusion 47: $1436-1446$
SCHECROON, N. and DELLOYE, CH. (2004). In vitro growth and osteoblastic differentiation of human bone marrow stromal cells supported by autologous plasma. Bone 35: 517-524.

SENSEBE', L. (2008). Clinical grade production of mesenchymal stem cells. Biomed Mater Eng 18: S3-10.

SERANKINCI, N., GULDBERG, P. and BURNS, J. S. (2004). Adult human mesenchymal stem cell as a target for neoplastic transformation. Oncogene 23: 5095.5098.

SHAHDADFAR, A., FRONDSDAL, K., HAUG, T., REINHOLT, F. P. and BRINCHMANN, J. E. (2005). In vitro expansion of human mesenchymal stem cells: choice of serum is a determinant of cell proliferation, differentiation, gene expression, and transcriptome stability. Stem Cells 23: 1357-1366.

SIMONSEN, J. L., ROSADA, C. and SERAKINCIN, N. (2002). Telomerase expression extends the proliferative life-span and maintains the osteogenic potential of human bone marrow stromal cells. Nat Biotechno/20: 592-596.

SONG,L. and TUAN, R. S. (2004). Transdifferentiation potential of human mesenchymal stem cells derived from bone marrow. FASEB J. 18: 980-982.

SOTIROPOULOU, P. A., PEREZ, S. A. And PAPAMICHAIL, M. (2007). Clinical grade expansion of human bone marrow mesenchymal stem cells. Methods Mol Bio/407: 245-263.

SOTIROPOULOU, P.A., PEREZ, S. A., SALAGIANNI, M., BAXEVANS, C. N. and PAPAMICHAIL, M. (2006). Characterization of the optimal culture conditions for clinical scale production of human mesenchymal stem cell. Stem Cel/s24: 462471.

SPEES, J. L., GREGORY, C.A. and SINGH, H. (2004). Internalized antigens must be removed to prepare hypoimmunogenic mesenchymal stem cells for cell and gene therapy. Mol Ther 9: 747-756.

SPITKOVSKY, D. and HESCHELE, J. (2008). Adult mesenchymal stromal cells for therapeutic applications. Minim Invasive Ther Allied Technol 17: 79-90.

STUTE, N., HOLTZ, K. and BUBENHEIM, M. (2004). Autologous serum for isolation and expansion of human mesenchymal stem cells for clinical use. Exp Hematol 32: $1212-1225$.

TAKEDA, Y., MORI, T. and IMABAYASHI, H. (2004). Can the life span of human marrow stromal cells be prolonged by bmi-1, E6, E7, and/or telomerase without affecting cardiomyogenic differentiation? J Gene Med 6: 833-845.

TAO, H., RAO, R. and MA, D. D. (2005). Cytokine-induced stable neurobal differentiation of human bone marrow mesenchymal stem cells in a serum/ feeder cell-free condition. Dev Growth Differ 47: 423-433.

TONTI, G. A., MANNELLO, F., CACCI, E. and BIAGIONI, S. (2008). Neural stem cells at the crossroads: MMPs may tell the way. Int $J$ Dev. Bio/(in press, doi: )

TOYODA, M., TAKAHASHI, H. and UMEZAWA, A. (2007). Ways for a mesenchymal stem cell to live on its own: maintaining an undifferentiated state ex vivo. Int $\checkmark$ Hemato/86: 1-4.

TULI, R., SEGHATOLESLAMI, M. R., TULI, S., WANG, M. L., HOZACK, W. J., MANNER, P. A., DANIELSON, K. G. and TUAN, R. S. (2003). A simple, highyield method for obtaining multipotential mesenchymal progenitor cells from trabecular bone. Mol Biotechno/23: 37-49.

VOGEL, J. P., SZALAY, K., GEIGER, F., KRAMER, M., RICHTER, W. and KASTEN, P. (2006). Platelet-rich plasma improves expansion of human mesenchymal stem cells and retains differentiation capacity and in vivo bone formation in calcium phosphate ceramics. Platelets 17: 462-469.

WAGNER, W., FELDMANN, R. E., SECKINGER, A., MAURER, M. H., WEIN, F., BLAKE, J., KRAUSE, U., KALENA, A., BURGERS, H. F., SAFFRICH, R., WUCHTER, P., KUSCHINSKY, W. and HO, A. D. (2006). The heterogeneity of human mesenchymal stem cell preparations-evidence from simultaneous analysis of proteomes and transcriptomes. Exp Hemato/34: 536-548.

WAGNER, W. and HO, A.D. (2007). Mesenchymal stem cell preparationscomparing apples and oranges. Stem Cell Rev 3: 239-248.

$U, X . Z$. (2008). Origin of cancer stem cells: the role of self-renewal and differentiation. Ann Surg Oncol 15: 407-414.

YAMAGUCHI, M., HIRAYAMA, F. and WAKAMOTO, S. (2002). Bone marrow stromal cells prepared using $A B$ serum and bFGF for hematopoietic stem cells expansion. Transfusion 42: 921-927.

YAMAMOTO, N., ISOBE, M. and NEGUSHI, A. (2003). Effects of autologous serum on osteoblastic differentiation in human bone marrow cells. JMed Dent Sci50: 63-69. 
ZHANG, Z. X., GUAN, L. X., ZHANG, K., WANG, S., CAO, P. C., WANG, Y. H., WANG, Z. and DAI, L. J. (2007). Cytogenetic analysis of human bone marrowderived mesenchymal stem cells passaged in vitro. Cell Biol Int 31: 645-648.

ZHENG, X.,BAKER, H. and HANCOCK, W. S. (2006). Proteomic analysis for the assessment of different lots of foetal bovine serum as raw material for cell culture. Part IV. Application of proteomics to the manufacture of biological drugs. Biotechnol Prog. 22: 1294-1300.
ZIMMERMAN, S., VOSS, M. and KAISER, S. (2003). Lack of telomerase activity in human mesenchymal stem cells. Leukemia 17: 1146-1149.

ZUK, P. A., ZHU, M., ASHJIAN, P., DE UGARTE, D. A., HUANG, J. I., MIZUNO, H., ALFONSO, Z. C., FRASER, J. K., BENHAIM, P. and HEDRICK, M. H. (2002). Human adipose tissue is a source of multipotent stem cells. $\mathrm{Mol} \mathrm{Biol} \mathrm{Cell} / 13$ : 4279-4295.

\section{Further Related Reading, published previously in the Int. J. Dev. Biol.}

See our recent Special Issue Fertilization, in honor of David L. Garbers and edited by Paul M. Wassarman and Victor D. Vacquier at: http://www.ijdb.ehu.es/web/contents.php?vol=52\&issue=5-6

See our recent Special Issue Ear Development edited by Fernando Giraldez and Bernd Fritzsch at: http://www.ijdb.ehu.es/web/contents.php?vol=51\&issue=6-7

DNA methylation state is preserved in the sperm-derived pronucleus of the pig zygote Young-Sun Jeong, Seungeun Yeo, Jung-Sun Park, Deog-Bon Koo, Won-Kyung Chang, Kyung-Kwang Lee and Yong-Kook Kang Int. J. Dev. Biol. (2007) 51: 707-714

An efficient method for isolation of murine bone marrow mesenchymal stem cells Samad Nadri, Masoud Soleimani, Reza H. HosSeni, Mohammad Massumi, Amir Atashi and Reza Izadpanah Int. J. Dev. Biol. (2007) 51: 723-729

Enhanced development of porcine embryos cloned from bone marrow mesenchymal stem cells Hai-Feng Jin, B. Mohana Kumar, Jung-Gon Kim, Hye-Jin Song, Yeon-Ji Jeong, Seong-Keun Cho, Sivasankaran Balasubramanian, Sang-Yong Choe and Gyu-Jin Rho Int. J. Dev. Biol. (2007) 51: 85-90

The instability of the neural crest phenotypes: Schwann cells can differentiate into myofibroblasts Carla Real, Corinne Glavieux-Pardanaud, Pierre Vaigot, Nicole Le Douarin and Elisabeth Dupin Int. J. Dev. Biol. (2005) 49: 151-159

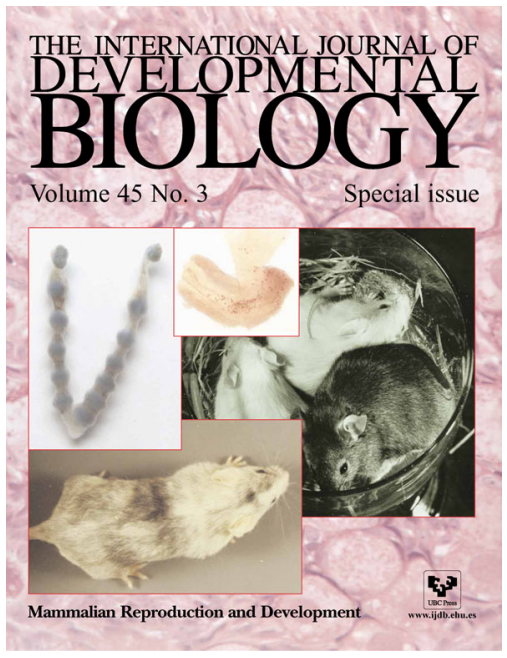

2006 ISI **Impact Factor $=3.577^{* *}$ 